\title{
Immunological and histological studies in primary biliary cirrhosis
}

S. HADZIYANNIS ${ }^{1}$, P. J. SCHEUER ${ }^{2}$, T. FEIZI, R. NACCARATO ${ }^{3}$, D. DONIACH, AND S. SHERLOCK

From the Departments of Pathology and Medicine, the Royal Free Hospital, and the Department of Immunology, the Middlesex Hospital, London

SYNOPSIS Thirty-one patients with primary biliary cirrhosis in whom adequate histological liver material was available were studied by immunological and histological methods. There was no statistically significant correlation between individual histological features and the level of serum mitochondrial antibodies. A relationship between the duration of symptoms and histological stage of the disease supports the present concept of its evolution. However, several stages were often identified in the same specimen. Four cases with negative mitochondrial antibodies were similar to the other 27 clinically and histologically.

Serum immunological studies in primary biliary cirrhosis have shown that most patients have non-organ-specific antibodies reacting with mitochondria in their serum (Doniach, Roitt, Walker, and Sherlock, 1966; Goudie, MacSween, and Goldberg, 1966; Paronetto, Schaffner, and Popper, 1967). In addition, sera may contain antibodies against smooth muscle and other tissue components (Paronetto, Schaffner, Mutter, Kniffen, and Popper, 1964; Doniach et al, 1966). A raised serum level of immunoglobulins (Ig), especially IgM, is commonly found (Hobbs, 1967; Feizi, 1968). These immune changes do not appear to correlate with biochemical abnormalities or with the duration of symptoms (Doniach et al, 1966; Feizi, 1968).

The purpose of this paper is to report a study of the relationship between immunological characteristics, histological features, and clinical duration in 31 patients with primary biliary cirrhosis. Particular attention was paid to the clinical and histological features in four cases in which serum mitochondrial antibodies were not found.

\footnotetext{
${ }^{1}$ Present address: 4th Department of Medicine, The Evangelismos Hospital, Athens, Greece.

${ }^{2}$ Requests for reprints may be addressed to Dr P. J. Scheuer, Royal Free Hospital, Gray's Inn Road, London WC1.

3Present address: Medical Pathology, University of Padua, Italy.

Received for publication 19 June 1969.
}

\section{Materials and Methods}

\section{PATIENTS}

Thirty-one patients with primary biliary cirrhosis were selected in whom adequate histological material was available and serum mitochondrial $:$ antibodies had been evaluated. Wedge biopsies $\underline{3}$. of liver were studied in 29 of the cases and 8 postmortem sections in two. In most cases needle $₹$ biopsies were also seen but were not analysed in 옹 detail. In 20 cases serum immunoglobulins had been estimated. For the purpose of correlating Ig values with mitochondrial antibody titres 11 N cases were added in which only needle biopsies $\sigma$ were available. The diagnosis of primary biliary $N$ cirrhosis rested on a combination of clinical, $\underset{\omega}{ }$ biochemical, and histological criteria (Sherlock, 1968), and in every case large duct biliary o obstruction was excluded at laparotomy.

\section{HISTOLOGY}

All sections were examined by two observers (S.H. and P.J.S.) and a questionnaire listing $47 \stackrel{\varnothing}{\varrho}$ histological features was completed by S.H. without knowledge of clinical or immunological $ᄋ$ findings. Features recorded included damage to and number of bile ducts of various sizes, pericholangitis, type and site of cellular infiltration, presence of cellular aggregates, granuloma 
formation, cholestasis, site and extent of fibrosis, liver cell degeneration, necrosis and regeneration, and nodule formation. Histological stages were determined according to the following criteria (Scheuer, 1967):

\section{Stage 1 (florid duct lesion)}

Presence of typical inflammatory lesions related to septal or large interlobular bile ducts.

\section{Stage 2 (ductular proliferation)}

Intense proliferation of bile ductules.

Stage 3 (scarring)

Extensive fibrosis with septum formation.

Stage 4 (cirrhosis)

Formation of regeneration nodules.

\section{SEROLOGY}

In 21 cases antibody tests and dates of the histological specimens were separated by less than one month. In the remaining cases the time interval was longer, but these were included in the study since the serum immunological changes in primary biliary cirrhosis seem to be persistent (Feizi and Doniach, unpublished observations). Many of the patients had been tested repeatedly. In addition to mitochondrial antibodies the presence of antinuclear factors and smooth muscle antibodies was determined by fluorescent methods as described by Doniach et al (1966). Complement-fixation tests were carried out using purified rat liver mitochondria and serum dilutions up to $1: 2048$. Serum immunoglobulin levels were determined by immunodiffusion (Feizi, 1968). The results of mitochondrial antibody tests were recorded as negative (immunofluorescent test negative), positive (immunofluorescent test positive and complementfixation test titre less than 32 ), or strongly positive (immunofluorescent test positiveand complementfixation test titre 32 or over). Antinuclear factors and smooth muscle antibodies were recorded as negative or positive, and serum IgG, IgA, and IgM levels as normal or increased. Normal serum immunoglobulin levels were taken as $530-1,400$, $52-540$, and $37-215 \mathrm{mg}$ per $100 \mathrm{ml}$ for IgG, IgA, and IgM respectively.

\section{Results}

The results of immunological tests are presented in Table $I$, and histological findings are summarized in Tables II and III.

\begin{tabular}{llcl}
\hline Test & Patients Examined & Positive or Raised \\
\hline Mitochondrial & & & \\
antibodies & 31 & $271(87 \%)$ \\
Antinuclear factors & 29 & $8(28 \%)$ \\
Smooth muscle & 23 & $7(30 \%)$ \\
antibodies & 20 & $11(55 \%)$ \\
IgG & 20 & $3(15 \%)$ \\
IgA & 20 & $14(70 \%)$ \\
IgM & &
\end{tabular}

Table I Results of serum immunological tests

${ }^{1} 14(45 \%)$ strongly positive

\begin{tabular}{ll} 
& \\
\hline Feature & Number Positive \\
\hline Lymphoid and plasma cell aggregates (total) & $28(90 \%)$ \\
Piecemeal necrosis present & $28(90 \%)$ \\
Cholestasis & $26(84 \%)$ \\
Acute bile duct damage and pericholangitis & $25(81 \%)$ \\
Reduced number of bile ducts & $25(81 \%)$ \\
Severe ductular proliferation & $19(61 \%)$ \\
Extensive fibrosis & $16(52 \%)$ \\
Lymphoid aggregates with germinal centres & $9(29 \%)$ \\
Granuloma & $7(23 \%)$ \\
Xanthoma & $4(13 \%)$ \\
Nodule formation & $4(13 \%)$ \\
Piecemeal necrosis severe & $3(10 \%)$ \\
\hline
\end{tabular}

Table II Main histological features in 31 patients

\begin{tabular}{lc}
\hline Stage Reached & Number of Cases \\
\hline Florid duct lesion & 8 \\
2 Ductular proliferation & 11 \\
3 Scarring & 6 \\
4 Cirrhosis & 4 \\
Undetermined & 2 \\
\hline
\end{tabular}

Table III Histological stage

seen in association with either negative or positive mitochondrial antibodies. The exception was lymphoid aggregates with germinal centres, these were found in portal tracts of nine patients. all of whom had mitochondrial antibodies? Damage to bile ducts of septal size was noted in 16 cases, but only once in the absence of mito chondrial antibodies. A reduction in the number of bile ducts was more common among patients. with strongly positive mitochondrial antibodies than in others. None of the above associations was statistically significant. No correlation waș found between any of the histological features and either antinuclear factors or smooth muscle antibodies.

Serum immunoglobulin levels were raised in 14 of 20 patients tested. IgG was increased in $11, \operatorname{IgA}$ in three, and IgM in 14. There was no correlation between histological findings and either IgG or IgA levels. Six patients out of seven in whose livers granulomas were found had increased serum levels of IgM, as had six out of seven patients with lymphoid aggregates having germinal centres.

Of the four patients (three female and ons male) with negative mitochondrial fluorescence two female patients had other autoantibodies in 


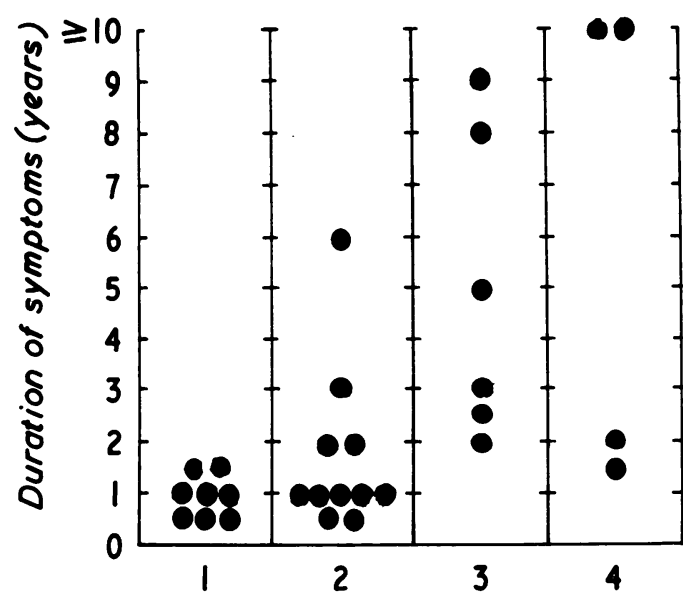

Histological stage

Fig. 1 Histological stage and duration of symptoms in 29 patients with primary biliary cirrhosis.

high titre; one had antinuclear factors detectable in serum dilutions up to $1: 400$, and the other repeatedly showed complement fixation in titres of $1: 32$ to $1: 64$ with tissue homogenates. In these four mitochondrial-negative patients clinical history, biochemical changes, and liver histology were all consistent with primary biliary cirrhosis (Sherlock, 1968). There was no history of exposure to drugs which might have caused cholestasis, and large duct biliary obstruction was excluded at laparotomy. In three of the patients serial liver biopsies were available and in two necropsy had been performed. In none of the cases was the histology that of chronic hepatocellular disease with superimposed cholestasis as described by Datta, Sherlock, and Scheuer (1963). The only unusual histological finding was the presence in one portal tract of calcified material surrounded by giant cells.

The following is an example of a case with repeatedly negative antibody tests. V.B., a woman, developed jaundice and pruritus in February 1963 at the age of 38. Jaundice persisted, and laparotomy was performed five months later. No biliary obstruction was found. Liver and spleen were enlarged. Following operation the jaundice and pruritus remained, with some fluctuation. In June 1965 a sudden haematemesis led to a further operation, at which gastric transection for bleeding oesophageal varices was carried out. A gastric ulcer was also found. The portal vein was thrombosed and partly recanalized. Three months later the patient was readmitted with fever and impending coma. She died eight days later of a massive cerebral haemorrhage. At necropsy the liver was large and green. There was endocarditis, and splenic and renal infarcts were found. Bronchopneumonia was present. Histological changes in the liver, initially those of early primary biliary cirrhosis with granuloma formation, had progressed through stage 2 to stage 3 of the disease, that of scarring. The serum biochemical changes had throughout been those of a cholestatic jaundice, with conjugated bilirubin levels up to $25 \mathrm{mg}$ per $100 \mathrm{ml}$ and alkaline phosphatase up to $64 \mathrm{King}$ Armstrong units per $100 \mathrm{ml}$. Serum transaminases were only slightly increased. Serum albumin was normal and there was an increase in $\alpha_{2}, \beta$, and $\gamma$ globulins.

CORRELATION OF HISTOLOGICAL

FINDINGS AND DURATION OF SYMPTOMS

Although there was no correlation between the immunological results and either duration of symptoms or histological stage reached, the $\mathrm{\omega}$ latter appeared to be related to the duration of i symptoms (Figure 1). Thus the mean duration of $\bullet$ symptoms from onset to biopsy or necropsy was 1.4 years for histological stages 1 and 2 combined (19 cases) and 6.3 years for stages 3 and 4 (10 cases). In the remaining two cases histological stage could not be satisfactorily assessed on the definitions adopted. There was considerable overlap between the two groups, and the range for stages 1 and 2 was one half to six years while that for stages 3 and 4 was one and a half to 20 years.

The above figures are based on the highest stage reached. Lesions typical of more than one stage were present together in the same biopsy in at least 17 of the 31 patients. Stages 1 and 3 were seen together in four cases, and stages 1 and 4 in two cases.

Piecemeal necrosis, destruction of liver cells at the edge of septa accompanied by chronic inflammatory infiltration, was noted in all but three patients and was thus surprisingly common. It was usually slight. Of the three cases in which it was not found one had reached histological stage 3 of the disease, and two had reached stage 4 . It was thus seen in all early cases.

CORRELATION BETWEEN DIFFERENT IMMUNOLOGICAL PARAMETERS

The correlation between serum IgM values and $\omega$ mitochondrial antibody titres in 31 patients is shown in Figure 2. Although three patients with negative mitochondrial fluorescence had normal IgM values and the mean level was highest in the cases with strongly positive mitochondrial antibodies, a wide range of IgM values of 60 to $800 \mathrm{mg}$ per $100 \mathrm{ml}$ was seen with both high and low titres and the differences were not statistically significant.

High serum IgM values were more commonly present in those cases with positive antinuclear factors but again the difference was not statistically demonstrable. All three patients with increased serum IgA levels had strongly positive mito- 


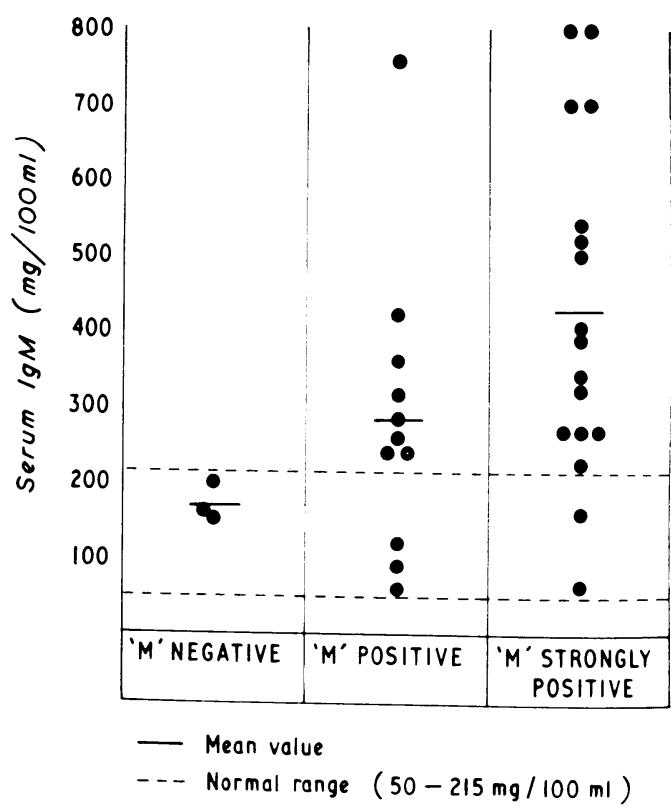

Fig. 2 Correlation of serum $\operatorname{Ig} M$ level and mitochondrial antibody titres in primary biliary cirrhosis. ' $M$ ' = mitochondrial antibody titre.

chondrial antibodies. IgG values were raised in half the patients irrespective of the antibody levels.

\section{Discussion}

No statistically significant correlation was found between the presence of mitochondrial antibodies and individual histological features. This may be explained partly by the relatively small number of cases available for detailed study, but also reflects the fact that many of the features studied, including mitochondrial antibodies themselves, were positive in most of the 31 cases.

Serum IgM values were raised in $70 \%$ of patients and high levels were frequently found in patients with a mitochondrial complementfixation titre in excess of 1:32. Similarly, all three patients with raised IgA had high mitochondrial titres. On the other hand, IgG values could not be correlated with the antibodies and this is in agreement with previous studies (Doniach et al, 1966) where it was shown that the total $\gamma$ globulin level was unrelated to mitochondrial antibody titres.

Several of the histological features listed in Table II were present in a very high proportion of cases. This is to be expected since some of them-such as bile duct damage, bile duct destruction, and cellular aggregates-are major criteria in the histological diagnosis of the disease.
Cholestasis, on the other hand, though verQ common, was often slight and usually periporta $\bar{p}$ whereas in most examples of cholestatic jaundice due to other causes cholestasis is typically centri lobular. The presence of piecemeal necrosis in. a high proportion of cases emphasizes that i $\overrightarrow{\overrightarrow{\text { F}}}$ primary biliary cirrhosis both biliary system and parenchyma are involved. Confusion with pres dominantly hepatocellular disease processes suc $\sqrt{5}$. as active chronic hepatitis may occur but is les.్ likely when operative wedge biopsies are seet than in needle specimens.

The correlation between histological stage an $\bar{\phi}$ duration of symptoms tends to confirm the validity of the stages as consecutive events in single disease process. In five cases, howevetके a late histological stage was reached withi层 three years of the onset of symptoms, suggesting that in some patients the disease is clinically silent for a considerable time or that it mays occasionally have a rapid evolution. The frequen? coexistence of several stages in the same liver seems to indicate that the disease progresse at varying rates in different parts of the liver on that fresh bile duct lesions continue to occur over the course of years.

Lastly, there is no indication in our series, as in that of Goudie et al (1966), that cases of primary biliary cirrhosis with negative mitos chondrial antibodies form a substantially difo ferent population from the rest as far as clinica\$ and histological features are concerned. This doe not exclude the possibility that their aetiology is different, and it may well be that the clinica $\$$ syndrome can be caused by a number of factors?

This work was supported by grants from the Prui dential Life Insurance Company (for S.H.) and the. Endowment Fund of the Royal Free Hospital (fon T.F.). R.N. was the holder of a NATO fellowship.

References

Datta, D. V., Sherlock, S., and Scheuer, P. J. (1963). Post-necrotic cirrhosis with chronic cholestasis. Gut, 4, 223-230.

Doniach, D., Roitt, I. M., Walker, J. G., and Sherlock, S. (1966). Tissue antibodies in primary biliary cirrhosis, acute chronic (lupoid) hepatitis, cryptogenic cirrhosis and otheN liver diseases, and their clinical implications. Clin. exped Immunol., 1, 237-262.

Feizi, T. (1968). Immunoglobulins in chronic liver disease. Gut, 9. 193-198.

Goudie, R. B., MacSween, R. N. M., and Goldberg, D. M市 (1966). Serological and histological diagnosis of primares biliary cirrhosis. J. clin. Path., 19, 527-538.

Hobbs, J. R. (1967). Serum proteins in liver disease. Proc. roy. Soc. Med., 60, 1250-1254.

Paronetto, F., Schaffner, F., Mutter, R. D., Kniffen, J. C., andD Popper, H. (1964). Circulating antibodies to bile ductula? cells in various liver diseases. J. Amer. med. Ass., 187ठ 503-506.

Paronetto, F., Schaffner, F., and Popper, H. (1967). Antibodies to cytoplasmic antigens in primary biliary cirrhosis an chronic active hepatitis. J. Lab. clin. Med., 69, 979-988.

Scheuer, P. J. (1967). Primary biliary cirrhosis. Proc. roy. Soc웡 Med., 60, 1257-1260.

Sherlock, S. (1968). Diseases of the Liver and Biliary System 4 th ed. Blackwell, Oxford. 